\title{
Awareness on Nutritional Status and Hygiene Practice of Street Children
}

\author{
Md Monoarul Haque* \\ Publication Secretary, Bangladesh Physiotherapy Association, Bangladesh
}

Submission: January 24, 2017; Published: January 30, 2017

*Corresponding author: Md Monoarul Haque, Publication Secretary, Bangladesh Physiotherapy Association, Bangladesh,

Email: monoarmunna@yahoo.com

\section{Editorial}

Bangladesh is densely populated country and approximately one-third of the population is teen ager. In our country number of children reside street in the big cities and towns particularly in Dhaka City. We usually observe them in roadside, train station, bus terminal, launch ghat etc. Actually they live an inhuman life and a significant portion of them are involved different kinds of activities as like puffed rice selling, newspaper selling, collecting discarded papers, water bottle etc. According to United Nation Development Programme (UNDP) report it is estimated that the number of street children in Bangladesh is currently over 600,000 of which $75 \%$ are in Dhaka city and estimated that in 2014 the number of children in a street situation was 930,000. There is growing warning that the number of the street children is set to raise as the urban population grows. Not only in Bangladesh street children are increasing the world over as part of the urban landscape. Evidence suggests that prevalence of disease among street children was 467 per 1000 children in Kenya and in India, the traditional approach towards care of children in difficult circumstances has been institutionalization.

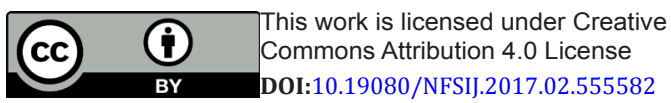

This practice started with the realization of the fact that there were a large number of children without parental care, vulnerable and in need of care and protection. Street children do not go to school; instead they sell things in the streets or do other jobs as their parents earn less money or do not work. In a country ranked 138th on the Human Development Index and where $50 \%$ of the population is living below the poverty line, these children represent the absolute lowest level in the social hierarchy, in the world's most densely populated nation. They usually eat whatever they get. Sometimes they have to pass hunger day. Most of the time they consume roadside foods without taking any personal hygienic preparation. Majority of them are barefooted. We often see street children do not practice hand washing before taking food; hand washing with soap is quite absent. Moreover they leave stool in roadside. Street children in Dhaka city are increasing and very little known about their nutritional conditions and health status. They lead a very vulnerable life and high risk of prone to different kinds of diseases. So it is essential to know nutritional status, hygiene practice and disease pattern of street children which may be helpful to implement any intervention related to them.

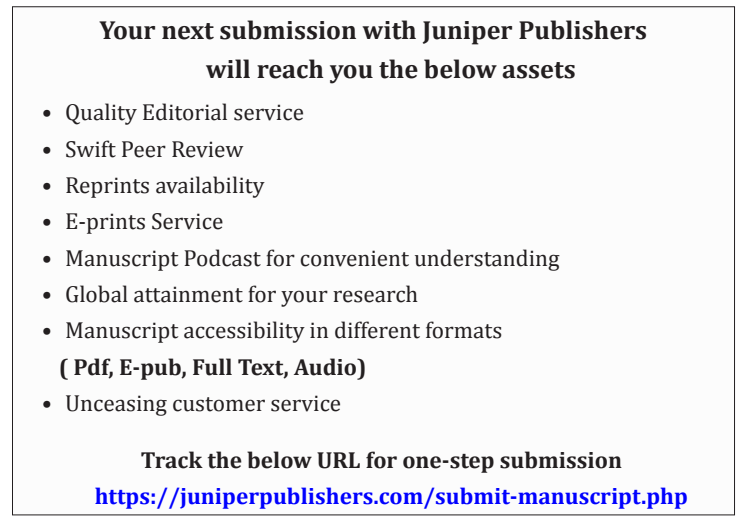

